\title{
EVALUATION OF INTERNAL FIT OF CAD/CAM IMPLANT ABUTMENTS WITH HYBRID AND INTERNAL HEX CONNECTIONS USING DIFFERENT MATERIALS
}

\author{
Khaled Elbanna*, Alaa Alqutub** and Shereen Kotb Salem***
}

\begin{abstract}
Objective: The aim of this study was to evaluate the internal fit of hybrid and internal hex connections using different materials.

Materials \& Methods: Forty abutments were divided into 2 groups according to connection type. Each group was subdivided into 4 subgroups according to material ( $\mathrm{Zr}, \mathrm{Ti}, \mathrm{Co}-\mathrm{Cr}$ and softmilled Co-Cr-Mo). Internal fit was measured using replica technique.
\end{abstract}

Results: All the samples had clinically acceptable gap values $\leq 150 \mu \mathrm{m}$ where internal hex connection had narrower gap than conical connection. Zirconia was the material with lowest gap values, followed by titanium and soft-milled Co-Cr-Mo. Co-Cr had the largest gap distance.

Conclusions: 1: Internal hex connection has better internal fit than hybrid connection with more consistent results among different materials. 2: Zirconia showed the best overall internal adaptation with consistent performance among the two connections used. 3: Low marginal gap distance of $\mathrm{CAD} / \mathrm{CAM}$ conical abutments may not necessarily indicate proper seating of the abutments.

KEYWORDS: Hybrid connections, Internal connections, CAD/CAM abutments, soft-milled Co-Cr-Mo, Zirconia

\section{INTRODUCTION}

Two-piece implant systems comprising implant and abutment are widely used in dental practice. A main disadvantage of this system is the inevitability of creating microgaps due to the misfit between the abutment and implant at the implant abutment interface (IAI). Misfit at the IAI is responsible for different mechanical (abutment fracture, screw loosening and fracture) and biologic (crestal bone loss, bacterial colonization, peri-implantitis) complications ${ }^{1-6}$. This can be attributed to the

* Assistant Professor, Fixed Prosthodontics Division, Department of Oral and Maxillofacial Surgery and Diagnostic Sciences, Faculty of Dentistry, Umm Al-Qura University, KSA.

** Assistant Professor, Department of Oral and Maxillofacial Surgery and Diagnostic Sciences, Faculty of Dentistry, Umm Al-Qura University, KSA.

*** Associate Professor, Fixed Prosthodontics Department, Faculty of Dentistry, October 6 University, Egypt. 
micromotion and rotation that can occur after loading ${ }^{7,8}$. Screw loosening, in return, enlarges the microgap ${ }^{9}$, hence, a pump is created due to the abutment micromovement inviting bacteria and macromolecules to migrate to the internal aspect of the implant ${ }^{10,11}$. There is no consensus on the acceptable gap distance at the IAI as some authors recommended a fit varying 1-49 $\mu \mathrm{m}^{12-14}$. A marginal misfit of $150 \mu \mathrm{m}$ was considered acceptable by Jemt ${ }^{15}$

Several connections have been designed and developed since the Brånemark's external connection in order to minimize the microgap and increase abutment stability. With a rotational misfit of $3-10^{\circ}$, which is far above the $<2^{\circ}$ needed to maintain a stable joint, a $6-48 \%$ prevalence of screw loosening has occurred with external connections ${ }^{16,17}$. Therefore, internal connections were introduced and showed overall improved microbial seal, less screw loosening, better esthetics and better joint strength ${ }^{18}$.

Internal connections are either: passive fit, where a gap exists between the components, or active fit, where there is actual contact between the components. Abutments with passive fit can be presented in various popular designs and shapes such as hexagonal, octagonal, spline, cylinder hex and tri-channel. Whereas abutments with active fit feature a conical connection with a Morse taper between the implant and abutment which is press fit together to form a cold-welded connection with significant friction ${ }^{19}$. With the application of compressive forces, deeper settling of the abutment occurs which minimizes the microgap and makes the two structures act as one unit leading to reduced microleakage and increased resistance to rotation and bending torques ${ }^{6}$.

A hybrid connection incorporates both taper and self-locking mechanisms to further minimize rotation and micromovement when higher forces are anticipated. However, a vertical discrepancy of 22.6-62.2 $\mu \mathrm{m}$ can be a disadvantage of the conical connection if it is not properly seated on the implant ${ }^{7,20}$.

Despite having superior fit ${ }^{8}$, the stock abutments have limited customization ability which is mainly limited to creating space for the final restoration by reduction of the occlusal/incisal surface. The finish line may not coincide with the actual mucosal contour. On top of that, the emergence profile can only be modified in the final crown due to the cylindrical form of the stock abutments which renders the esthetic outcome dependent on the deep placement of the finish line, which in turn, hinders proper cement removal ${ }^{21,22}$. Consequently, the optimum way to enhance the emergence profile and the relation between the gingival depth and adjacent dental structure is with the customized abutment ${ }^{23}$. Customization of the abutment can be achieved by several ways; casting either on premachined connections or fully casting the abutment. A custom-made abutment on a Ti-base is reported to yield favorable outcomes ${ }^{24}$.

CAD/CAM abutments can be fabricated in numerous ways; top-to-bottom milling of the whole abutment or milling only the coronal part of the abutment with a ready-made pre-machined connection. Several studies evaluated milled abutments with regards to microgap formation and machining tolerance. Machining tolerance is defined as the amount of acceptable variance in the dimension of a part. Many studies highlighted the necessity of reduction of machining tolerance of implant components to make sure of the intimate fit of the machined parts and the implant to avoid the mechanical and biological complications ${ }^{25-27}$.

Titanium has been used for custom made abutments. Numerous researchers found it comparable to stock abutments in terms of vertical gap of the IAI ${ }^{28-30}$ while from the plethora of the esthetic ceramic materials used in the dental field, zirconia has been the mostly used abutment/ 
crown material in implant prosthodontics due to its biocompatibility, superior strength and good esthetics ${ }^{31-33}$.

$\mathrm{Co}-\mathrm{Cr}$ has been used for the fabrication of customized abutments to replace the much more expensive precious alloys especially after the increase in gold prices. The non- precious alloy was initially used either in the full-cast form, where the abutment including the connection is casted, or casted on a pre-machined connection. However, the success of these types, especially the full-cast type, depends to a large extent on the technician's skill and expertise ${ }^{33,34}$. CAD/CAM milled $\mathrm{Co}-\mathrm{Cr}$ has the advantages of minimizing human errors, time and cost in addition to a smooth-surface precise finish ${ }^{35}$.

Another approach for fabricating customized Co-Cr abutments is by milling a wax-like texture pre-sintered disc which allows the material to be dry milled effortlessly. During the subsequent sintering process under shielding gas atmosphere, the frameworks achieve their final material properties. Any conventional $\mathrm{Co}-\mathrm{Cr}$ porcelain can then be used for veneering. The manufacturers extend the indications from conventional crown and bridge work to multi-unit, screw-retained restorations and custom abutments on titanium bases ${ }^{36}$. Nonetheless, they don't claim that implant connections can be fabricated using this technique.

This study aims to evaluate the effect of milling different types of connections and different types of materials on the gap distance at the IAI. The null hypotheses of this study are:

1. There is no difference in gap distance at the IAI between internal hexagonal connection and hybrid connection.

2. There is no difference in gap distance at the IAI between custom-made milled zirconia, titanium, Co-Cr and soft-milled Co-Cr-Mo.

\section{MATERIALS AND METHODS}

A total number of 40 implants were used in this study and divided into two equal groups $(n=20)$ according to connection design: Group 1: internal hex (Torx ${ }^{\circledR}$, Tube-in-Tube) connection (Classic Sky, Bredent GmbH, Germany) and Group 2: hybrid $5^{\circ}$ morse taper combined with internal hex anti-rotation feature (Connexa) connection (EvLine, B\&B Dental S.r.l, Italy). Each group was further subdivided into four equal subgroups according to material of fabrication $(n=5)$. Zirconia (Ceramill Zolid HT, Ammann Girrbach, Austria), Titanium Grade V (imes-icore $\mathrm{GmbH}$, Eiterfeld, Germany), Co-Cr (Remanium Star MD II, Dentaurum, Germany) and soft-milled Co-Cr-Mo (Ceramill Sintron, Ammann Girrbach, Austria) were assigned to subgroups Z, T, $\mathrm{C}$ and $\mathrm{S}$ respectively as shown in Table 1 .

\section{Sample preparation}

Epoxy resin (Chemapox 150, CMB, Giza, Egypt) was mixed and poured into ice cube mould. Twenty implants with internal hex connection and $4 \mathrm{~mm}$ width and $10 \mathrm{~mm}$ length (Classic Sky, Bredent $\mathrm{GmbH}$, Germany) and 20 hybrid connection implants

TABLE (1): Sample grouping.

\begin{tabular}{lcccc}
\hline & $\begin{array}{c}\text { Subgroup Z } \\
(\text { Zirconia })\end{array}$ & $\begin{array}{c}\text { Subgroup T } \\
\text { (Titanium) }\end{array}$ & $\begin{array}{c}\text { Subgroup C } \\
(\text { Co-Cr })\end{array}$ & $\begin{array}{c}\text { Subgroup S } \\
\text { (Soft-Milled Co-Cr-Mo) }\end{array}$ \\
\hline $\begin{array}{l}\text { Group 1: Hybrid connection } \\
\text { (Connexa) }\end{array}$ & $1 \mathrm{Z}$ & $1 \mathrm{~T}$ & $1 \mathrm{C}$ & $1 \mathrm{~S}$ \\
\hline $\begin{array}{l}(\mathrm{n}=5) \\
\text { Group 2: Internal Hex }\end{array}$ & $2 \mathrm{Z}=5)$ & $(\mathrm{n}=5)$ & $(\mathrm{n}=5)$ \\
(Torx, Tube-in Tube) & $(\mathrm{n}=5)$ & $\begin{array}{c}2 \mathrm{~T} \\
(\mathrm{n}=5)\end{array}$ & $\begin{array}{c}2 \mathrm{C} \\
(\mathrm{n}=5)\end{array}$ & $2 \mathrm{~S}$ \\
\hline
\end{tabular}


with $4 \mathrm{~mm}$ width and $10 \mathrm{~mm}$ length (EvLine, B\&B Dental S.r.l, Italy) were inserted vertically into the resin using dental surveyor until $2 \mathrm{~mm}$ from the face of the implant were left uncovered and the resin was left to set for 24 hours.

Scan bodies were fixed to one implant of each group and scanned to acquire the implant position and to start the design of the abutments using a CAD software (Exocad GmbH, Darmstadt, Germany) with internal hex connection for Group 1 and a copy was made for the same design but with hybrid connection for Group 2. Both connection types were acquired from the software library. Figure 1

Each design was milled in a 5-axis CNC milling machine (ED5X, Emar, Egypt) from four different materials; Zirconia (Ceramill Zolid HT, Ammann Girrbach, Austria), Titanium Grade V (imes-icore $\mathrm{GmbH}$, Eiterfeld, Germany), Co-Cr (Remanium Star MD II, Dentaurum, Germany) and soft-milled

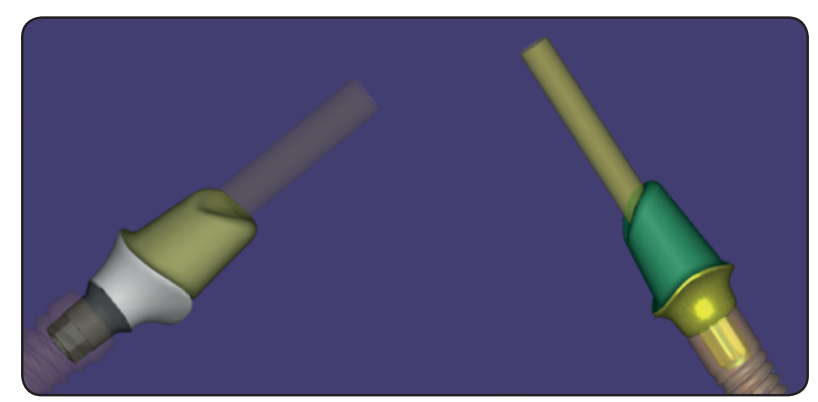

Fig. (1): CAD of the abutment for the two different connections
Co-Cr-Mo (Ceramill Sintron, Ammann Girrbach, Austria). After milling, the zirconia and soft-milled Co-Cr-Mo abutments were sintered in sintering furnaces (Ceramill Therm 3, Ammann Girrbach, Austria and Ceramill Argotherm 2, Ammann Girrbach, Austria respectively) according to manufacturers' instructions. Figures 2 and 3

Fast setting light body addition silicone impression material (Elite HD+, Zhermack, Italy) was mixed with a mixing gun and applied to the abutment connection and the abutment was screwed at $25 \mathrm{Ncm}$ with the respective screw for each implant system with the system's screwdriver and torque wrench. After setting of the light body, screw was untightened, and the abutment was removed. Heavy body addition silicone (Elite HD+, Zhermack, Italy) was injected over the light body to stabilize it and was removed from the implant after polymerization to form a rubber index. Figures 4, 5

The rubber index was cut at three levels; $1 \mathrm{~mm}$ from the apical end of the abutment connection (Bottom), $1 \mathrm{~mm}$ from the coronal end of the abutment connection (Top) and in the middle using a stainless-steel razor in both groups, however the middle section in Group1 was cut in the conical part $1 \mathrm{~mm}$ above the anti-rotation feature of the hybrid connection (Middle). Each section was divided by six lines to obtain 12 measuring points. Figures 6, 7 .

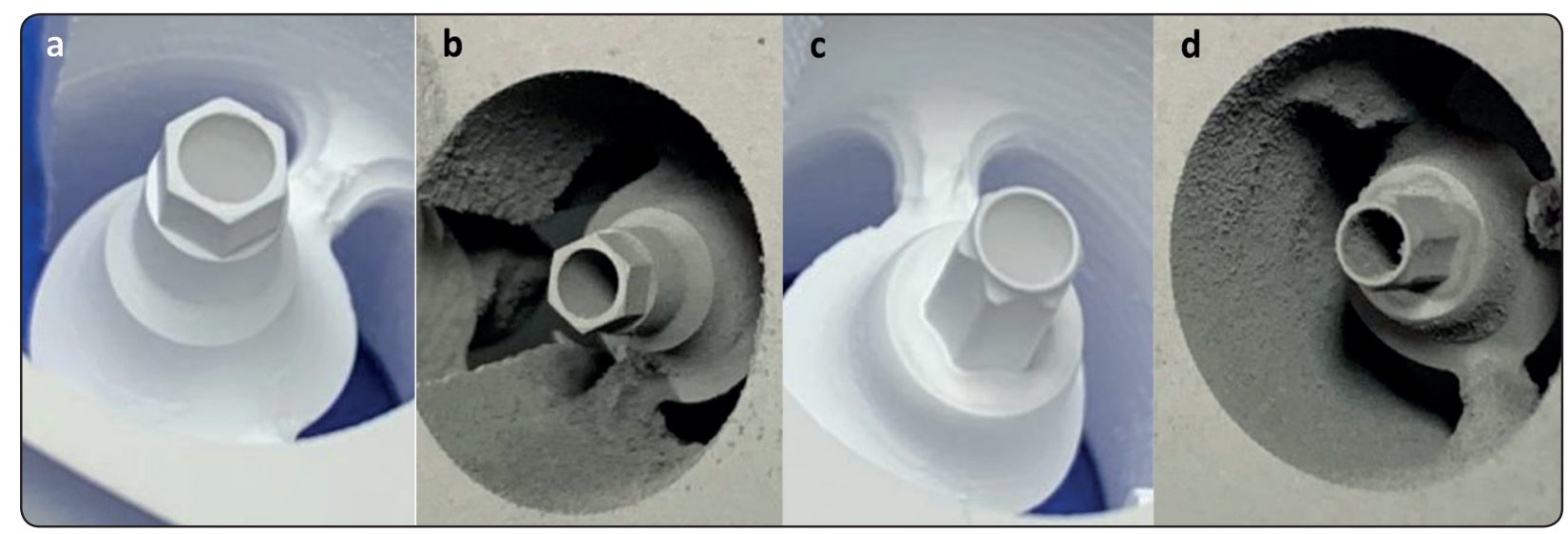

Fig. (2): Pre-sintered zirconia and soft-milled Co-Cr-Mo connections of Group 1 (a, b) and Group 2 (c, d) 


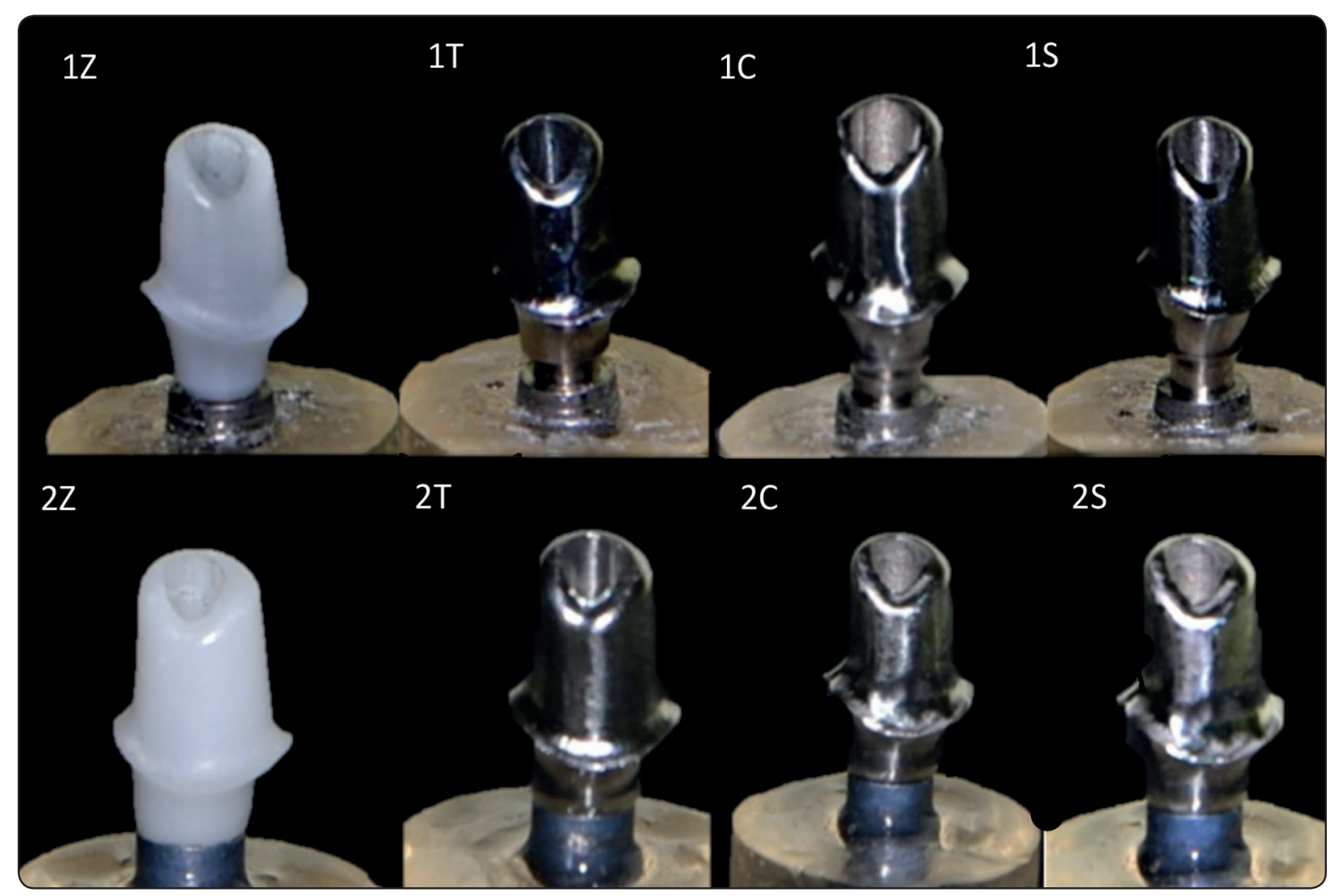

Fig. (3): Different abutments seated on implants

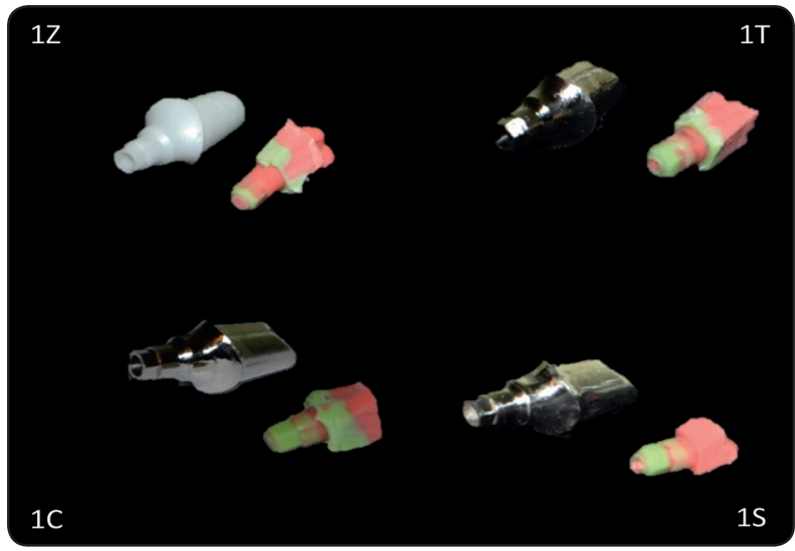

Fig. (4): Group 1 abutments and rubber indices

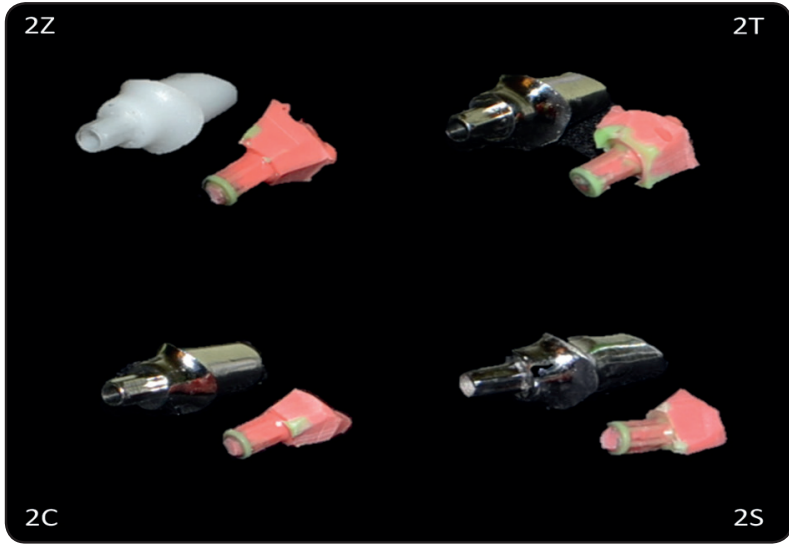

Fig. (5): Group 2 abutments and rubber indices 


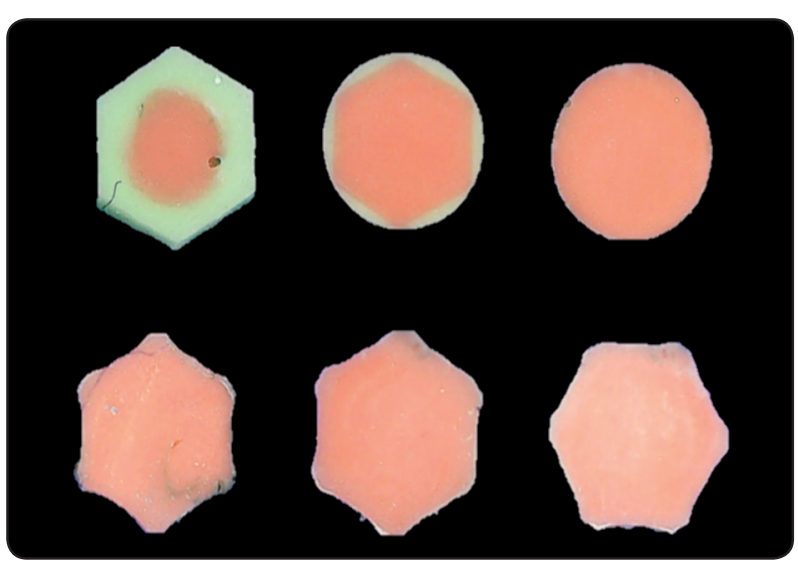

Fig. (6): Three sections were cut in each abutment connection: Group 1 (up), Group2 (down): Bottom section (left), Middle section (middle) and Top section (right).

The thickness of the light body at each measuring point was evaluated by a single operator using a calibrated digital microscope (HotViewer, China) at 50x magnification.

The data were tabulated, mean values and standard deviations were calculated, and statistical analysis was performed using statistics analysis software (SPSS 28.0, IBM, Chicago, USA).

The data were tested for normality using ShapiroWilk test and abnormal distribution was found among the different groups. Mann-Whitney U test was used for comparison between connection types and Kruskall Wallis test was used for comparison between different materials and the interaction of connection type and material at each section and overall. Confidence interval of $95 \%$ was set to test statistical significance for all tests.

\section{RESULTS}

Internal adaptation mean value was found to be significantly higher $(p \leq 0.001)$ for Group 1 (103.8 $\mu \mathrm{m})$ compared to Group $2(18.5 \mu \mathrm{m})$. The distribution of the internal gap values was different across different sections; Group 1 showed higher mean values for the Bottom and Middle sections, whereas Group 2 showed higher mean for the top section. Table 2, Figure 8

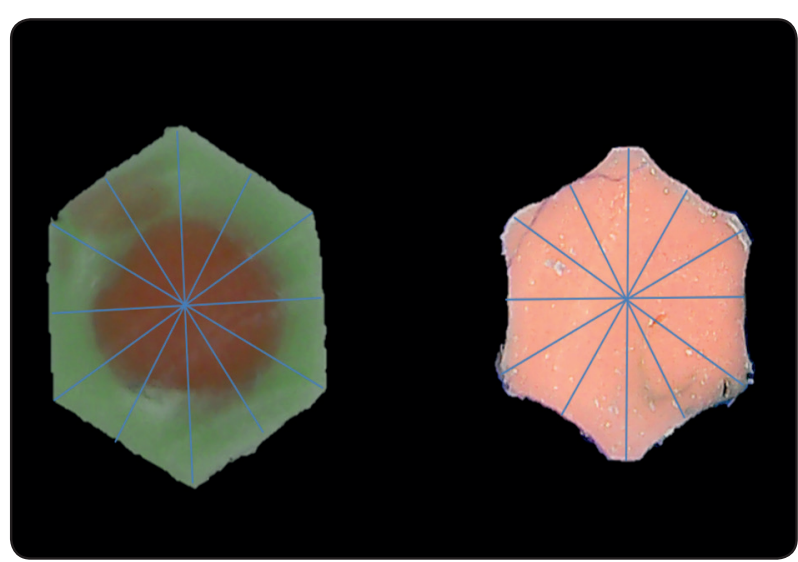

Fig. (7): The lines dividing each section to determine the measurement points: Group 1 (left), Group2 (right)

Zirconia abutments showed the lowest mean value $(16.3 \mu \mathrm{m})$ with a statistically significant difference $(p \leq 0.001)$ in each section and in the overall compared to the other material types both in Bottom and Middle sections and the overall measurements, however the difference was insignificant in the Top section. There was no difference between the means of Titanium and soft milled Co-Cr-Mo (73.2 $\mu \mathrm{m}, 76.7 \mu \mathrm{m}$ respectively) while $\mathrm{Co}-\mathrm{Cr}$ showed the largest significant mean gap value $(78 \mu \mathrm{m})$. Table 3 , Figure 9.

TABLE (2): Means $(\mu \mathrm{m})$ and standard deviations of internal gap distance for overall and different sections of different groups.

\begin{tabular}{|c|c|c|c|}
\hline & & Group 1 & Group 2 \\
\hline \multirow{4}{*}{ 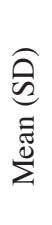 } & Bottom & $246.5(138.3)^{\mathrm{b}}$ & $17.2(10.4)^{\mathrm{a}}$ \\
\hline & Middle & $62.3(51)^{\mathrm{b}}$ & $20.2(12.4)^{\mathrm{a}}$ \\
\hline & Top & $1.97(2.6)^{\mathrm{a}}$ & $18(10.2)^{\mathrm{b}}$ \\
\hline & Overall & $103.6(134.4)^{b}$ & $18.5(11)^{\mathrm{a}}$ \\
\hline
\end{tabular}

Cells with different letters ${ }^{(a, b, c)}$ in the same row have statistically significant difference (Mann Whitney $p \leq 0.05$ )

Subgroup 2T $(15.6 \mu \mathrm{m})$ showed the lowest mean overall internal gap values with no significant difference with subgroups $1 \mathrm{Z}, 2 \mathrm{Z}$ and $2 \mathrm{~S}$ followed by $2 \mathrm{C}$ which had significant difference as well with subgroups 1T, 1C and $1 \mathrm{~S}$ which showed 
the highest mean value $(137 \mu \mathrm{m})$. However, the distribution of the internal gap was different across different sections; subgroups $2 \mathrm{~T}(15 \mu \mathrm{m})$ and $1 \mathrm{~S}$ (334 $\mu \mathrm{m})$ showed the lowest and highest values for the Bottom section respectively, while for Middle section, subgroups $2 \mathrm{~S}(15.8 \mu \mathrm{m})$ and $1 \mathrm{~T}(81 \mu \mathrm{m})$ took the first and last rank respectively. As for Top section, subgroup $1 \mathrm{~S}(1.6 \mu \mathrm{m})$ had the lowest mean and subgroup $2 \mathrm{C}(25 \mu \mathrm{m})$ had the highest mean internal gap distance. Table 4, Figures 10-12

TABLE (3): Means ( $\mu \mathrm{m})$ and standard deviations of internal gap distance for overall and different sections of different subgroups.

\begin{tabular}{|c|c|c|c|c|c|}
\hline & Subgroup & $\begin{array}{c}\text { Z } \\
\text { (Zirconia) }\end{array}$ & $\begin{array}{c}\mathrm{T} \\
\text { (Titanium) }\end{array}$ & $\begin{array}{c}\mathrm{C} \\
(\mathrm{Co}-\mathrm{Cr})\end{array}$ & $\begin{array}{c}\text { S } \\
\text { (Soft-milled Co-Cr-Mo) }\end{array}$ \\
\hline \multirow{4}{*}{ 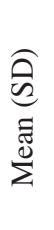 } & Bottom & $22.8(14.3)^{\mathrm{a}}$ & $162.3(151.8)^{\mathrm{b}}$ & $167(156.6)^{b}$ & $175.4(166.9)^{\mathrm{b}}$ \\
\hline & Middle & $17.3(5.5)^{\mathrm{a}}$ & $48.4(48.4)^{\mathrm{b}}$ & $53.5(43.3)^{\mathrm{c}}$ & $46(47.6)^{b}$ \\
\hline & Top & $8.6(8.2)^{\mathrm{a}}$ & $8.9(8.2)^{\mathrm{a}}$ & $13.5(15.5)^{\mathrm{a}}$ & $8.9(9.6)^{\mathrm{a}}$ \\
\hline & Overall & $16.3(11.58)^{\mathrm{a}}$ & $73.2(113)^{\mathrm{b}}$ & $78(114.3)^{c}$ & $76.7(123)^{\mathrm{b}}$ \\
\hline
\end{tabular}

Cells with different letters ${ }^{(a, b, c)}$ in the same row have statistically significant difference (Kruskal Wallis $p \leq 0.05$ )

TABLE (4): Means $(\mu \mathrm{m})$ and standard deviations of internal gap distance for different sections and overall of different groups and subgroups.

\begin{tabular}{|c|c|c|c|c|c|c|c|c|c|}
\hline \multicolumn{2}{|c|}{$\begin{array}{l}\text { Group/Subgroup } \\
\text { interaction }\end{array}$} & $1 Z$ & $1 \mathrm{~T}$ & $1 \mathrm{C}$ & $1 \mathrm{~S}$ & $2 Z$ & $2 \mathrm{~T}$ & $2 \mathrm{C}$ & $2 \mathrm{~S}$ \\
\hline \multirow{4}{*}{ 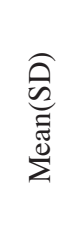 } & Bottom & $26(14)^{c}$ & $310(46)^{\mathrm{d}}$ & $316(64)^{d}$ & $334(72)^{d}$ & $19(13)^{\mathrm{b}}$ & $15(11)^{\mathrm{a}}$ & $18(7)^{\mathrm{b}}$ & $17(9)^{b}$ \\
\hline & Middle & $19(3)^{b}$ & $81(51)^{\mathrm{d}}$ & $74(52)^{\mathrm{d}}$ & $76(51)^{\mathrm{d}}$ & $16(7)^{\mathrm{a}}$ & $16(6)^{\mathrm{a}}$ & $33(16)^{c}$ & $15.8(8)^{\mathrm{a}}$ \\
\hline & Top & $2.2(3.1)^{\mathrm{a}}$ & $2(2.4)^{\mathrm{a}}$ & $1.9(2.6)^{\mathrm{a}}$ & $1.6(2.2)^{\mathrm{a}}$ & $15(7)^{b}$ & $16(6)^{b}$ & $25(14)^{\mathrm{c}}$ & $16(9)^{b}$ \\
\hline & Overall & $15.7(13)^{\mathrm{a}}$ & $131(137)^{c}$ & $131(143)^{\mathrm{c}}$ & $137(151)^{\mathrm{c}}$ & $17(9)^{\mathrm{a}}$ & $15.6(8)^{\mathrm{a}}$ & $25(15)^{\mathrm{b}}$ & $16(8.6)^{\mathrm{a}}$ \\
\hline
\end{tabular}

Cells with different letters ${ }^{(a, b, c, d)}$ in the same row have statistically significant difference (Kruskal Wallis $p \leq 0.05$ )

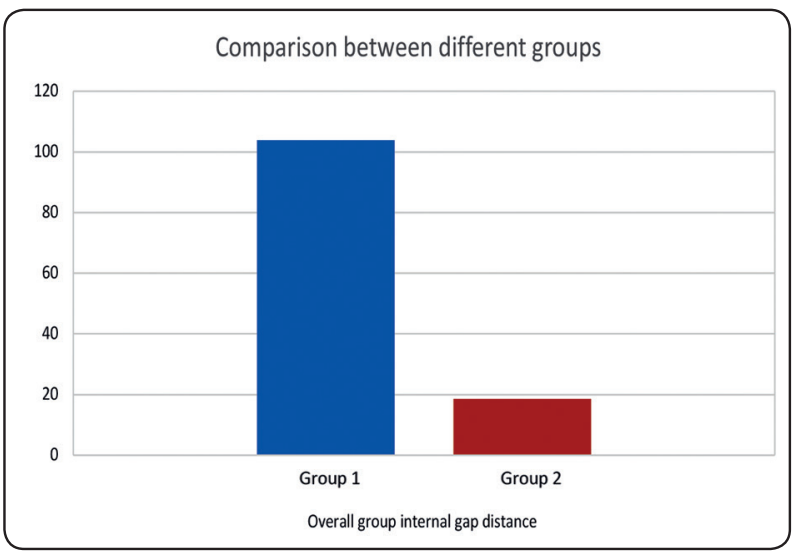

Fig. (8): Bar chart showing the means $(\mu \mathrm{m})$ of overall internal gap distance of different groups.

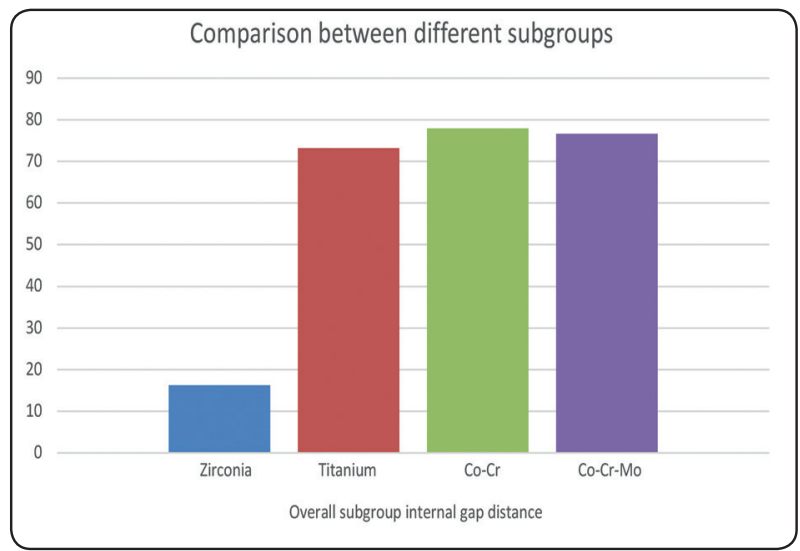

Fig. (9): Bar chart showing the means $(\mu \mathrm{m})$ of overall internal gap distance of different subgroups. 


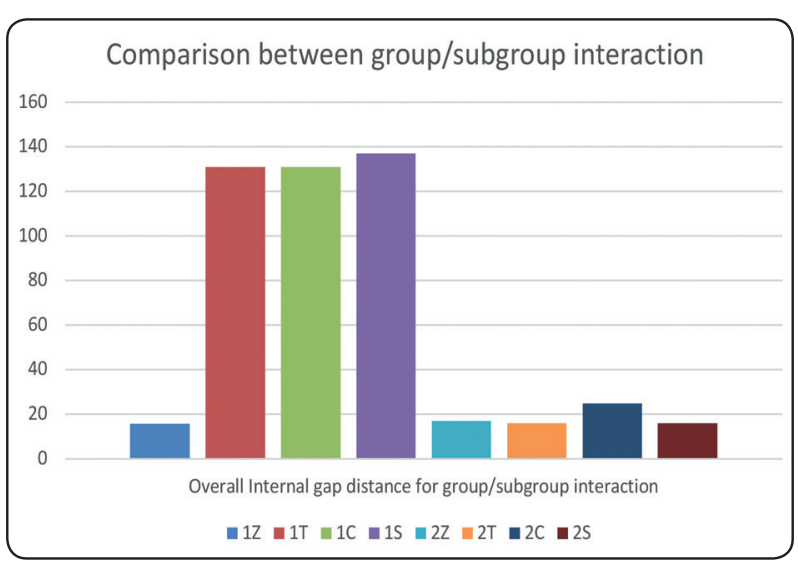

Fig. (10): Bar chart showing means $(\mu \mathrm{m})$ of overall internal gap distance of different groups and subgroups.

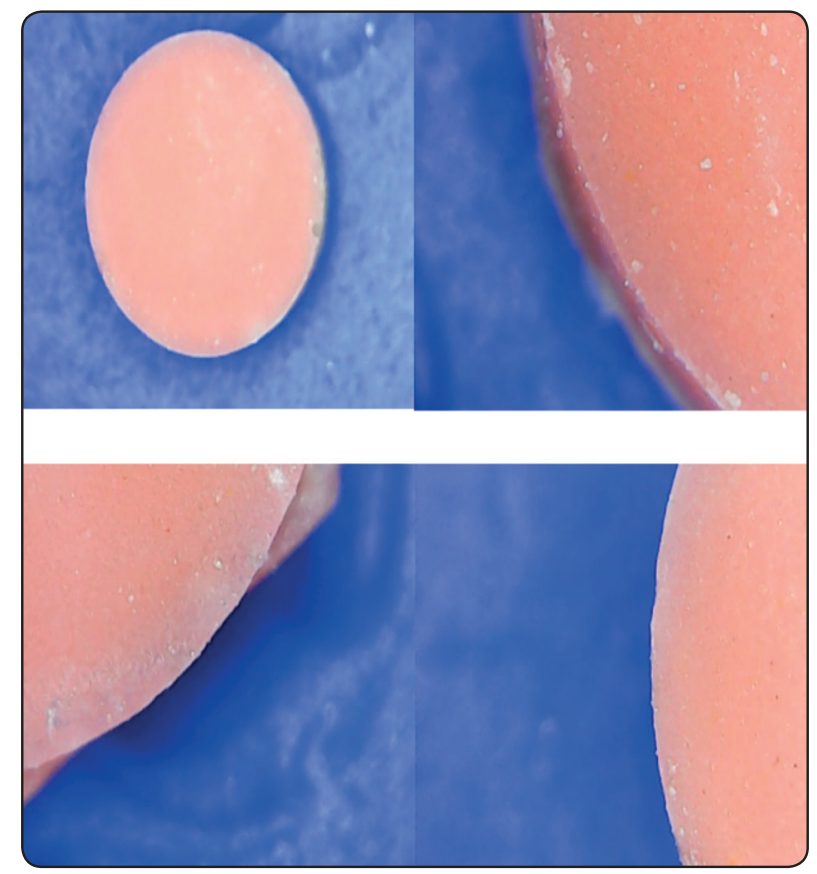

Fig. (12): Minimal internal gap distance in the conical Top section of Group 1 samples at 50x and 1000x magnification.

\section{DISCUSSION}

Customization of abutments can best achieve optimum relation with the gingival tissues and the adjacent teeth where a subgingival margin between $0.5-1 \mathrm{~mm}$ is placed ${ }^{29}$. Proper customization can be achieved by CAD/CAM abutments which combine predictable fit and durability that can be gained from stock abutments together with the ability to

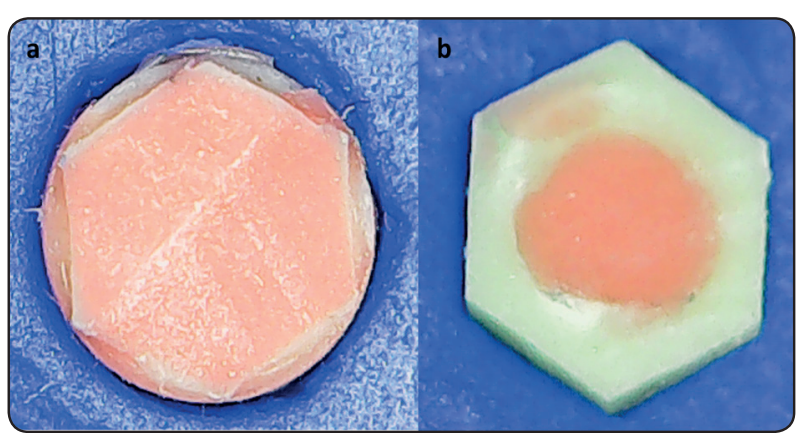

Fig. (11): A great difference in seating between $1 \mathrm{Z}$ (a) and $1 \mathrm{~S}$ (b) is apparent with minimal gap in $1 \mathrm{Z}$ and a huge gap in $1 \mathrm{~S}$

modify different prosthetic restoration parameters such as emergence profile, corrected angle, location of the finish line, external contour and thickness of the restoration ${ }^{37,38}$.

In addition to accuracy, durability and the simplicity of the construction procedure, the versatile range of materials that can be used is considered a huge benefit of CAD/CAM dental restoration including implant abutments. CAD/CAM is considered the only way to manufacture high-strength ceramic abutments until this day. Those custom-made CAD/CAM abutments can be either machined from the top down including the implant connection or milled from blocks with pre-machined connections. However, only the former method can be used for the manufacturing of custom-made zirconia abutments ${ }^{29,37}$.

Several studies have evaluated the fit of CAD/ CAM abutments with various connection types and materials ${ }^{39-45}$. Different methods were used to evaluate the implant-abutment fit such as replica technique $^{42,43}, \mathrm{SEM}^{44,45}$, radiographic examination ${ }^{34,46,47}$, and micro $\mathrm{CT}^{41}$.

Replica technique was used in this study due to the capability of this technique to measure the internal adaptation, ease of the technique, abundance of literature describing the technique and availability of needed materials. Other techniques have one or 
more of the disadvantages of being too expensive, aggressive, need special equipment or being limited to measuring the marginal gap only ${ }^{39-45}$.

Two types of internal connections were tested in this study; Connexa: a hybrid conical-hex connection (Group 1) and a Torx ${ }^{\circledR}$, tube-in-tube, internal hexagonal connection (Group 2), possessing active-fit with anti-rotation feature and passive-fit respectively.

Both null hypotheses were rejected as there was a significant difference between both types of connections and between the four materials used. The results of this study show that Group 1 has higher internal gap distance mean value $(103.8 \mu \mathrm{m})$ than Group $2(18.5 \mu \mathrm{m})$. Apart from the upper part of the conical section of the connection, there seems to be very poor fit specially in the anti-rotation hexagonal section of Group 1 samples. This indicates a failure to completely seat the abutments despite torquing the screw to the recommended force.

This could be a result of the failure of the milling machine to accurately mill the conical part to the correct dimension or angle which may have rendered the first contact area with the implant a little larger than it should be. This can be demonstrated by the intimate fit at the implant face and the lack of fit more apically, making the standard diameter of the implant face engage the relevant diameter of the abutment but at a more apical direction in relation to the abutment.

The conical surface of the hybrid abutment with its circular nature and the $5^{\circ}$ morse taper may complicate the milling of the abutment connection. A minimal discrepancy in the diameter or the angle of the conical part may lead to incomplete seating of the abutment creating a large gap between the implant and the abutment. Incompatible drill size of the milling drill with the corresponding implant angle and the change in radius are reported to be contributing factors of the final fit of CAD/CAM abutments ${ }^{48,49}$.
Zirconia performed well despite the type of connection. Titanium, Co-Cr and soft-milled Co-Cr-Mo were affected by the type of connection. Zirconia showed the lowest internal gap value $(16.3 \mu \mathrm{m})$ between all the materials tested followed by titanium, finally soft-milled Co-Cr-Mo and $\mathrm{Co}-\mathrm{Cr}$ had the highest values. This may be due to that zirconia abutments were the only ones to be adequately seated in Group 1. The soft nature of the zirconia during milling may increase the accuracy of the milling procedure. This could explain also why the $\mathrm{Co}-\mathrm{Cr}$ had the highest mean values as $\mathrm{Co}-\mathrm{Cr}$ is the stiffest material used in this study which may have affected the wear and bending of the drilling instruments ${ }^{48}$. It was reported that stiffness of the abutment material was related to the passivity and preload maintenance ${ }^{29}$.

Sandoval R (2021) ${ }^{45}$ and Sui et al (2014) ${ }^{50}$ found a marginal gap of $(14.18 \mu \mathrm{m})$ and $(19.38 \mu \mathrm{m})$ at the IAI for milled internal hex zirconia abutments respectively which is comparable to the results obtained by this study $(16.3 \mu \mathrm{m})$. Sae-Lee $\mathbf{D}$ et al (2018) ${ }^{42}$ had mean internal gap of $(88.4 \mu \mathrm{m})$ for customized titanium bases which is in accordance with the mean of overall titanium abutments of (73 $\mu \mathrm{m})$ found in this study.

On the contrary to this study, Barbosa $\mathbf{J r} \mathbf{S}$. et al (2020) ${ }^{29}$ found that the misfit for external hex abutments made of titanium $(11.1 \mu \mathrm{m})$ is better than that of zirconia abutments $(25.3 \mu \mathrm{m})$. Molinero-Mourelle P et al (2021) ${ }^{41}$ compared the angular misfit of milled $\mathrm{Co}-\mathrm{Cr}$ and zirconia conical abutments and found no significant difference between them (2.26 and $2.57 \mu \mathrm{m}$ respectively) but they were much better than laser sintered and cast Co-Cr. Gonzalo E et al (2020) ${ }^{30}$ evaluated the marginal misfit of milled titanium abutments for different implant systems and mean values between 0-2.32 $\mu \mathrm{m}$ were measured. Yuzugullu B and Avci $\boldsymbol{M}$ (2008) ${ }^{28}$ found mean vertical gap of 2.5-3.2 $\mu \mathrm{m}$ for zirconia and titanium abutments. 
Soft-milled Co-Cr-Mo was used to fabricate implant abutments including the connections between them. Despite being milled in a soft state which can contribute to easier and more accurate milling, sintering of the soft material causes dimensional changes that may affect the internal adaptation of the abutment. A slight decrease in the shrinkage, estimated by $10 \%$ by the manufacturer, can lead to improper fit due to early contact between the conical part of the abutment and the implant. Ramalho I (2020) ${ }^{43}$ evaluated misfit volume of CAD/CAM soft-milled Co-Cr-Mo to machined and cast abutments and found that the soft-milled Co$\mathrm{Cr}-\mathrm{Mo}$ had the largest values of the three groups.

The different results could be explained by the fact that different abutment connections or different measurement techniques were used, or measurement of marginal adaptation only compared to overall internal adaptation in this study. Mean values of Top section of Group 1, which is the nearest area to the margin, had as low mean values as those mentioned above.

The results of this study indicates that all the tested groups and subgroups were within the clinically accepted range of $150 \mu \mathrm{m}^{15,51}$. This is in accordance with several authors who concluded that CAD/CAM milled abutments can be a valid alternative to stock and cast abutments ${ }^{36,41,42,52}$.

Nevertheless, a thorough look in the mean values of Group 1 Bottom and Top sections shows that despite that subgroups $1 \mathrm{~T}, 1 \mathrm{C}$ and $1 \mathrm{~S}$ had the lowest mean values at the Top section, which may indicate good margin adaptation at the IAI, very large internal gap was found in the Bottom section with the highest mean values between all other samples. This indicates that the abutments had premature contact with the implant at the top and failed to be completely seated in their places.

This finding could rule out the significance of margin gap measurement in customized conical abutments as the presence of a clinically acceptable gap margin at the IAI does not necessarily mean that the abutment is completely seated into the implant due to the absence of a butt margin or landmark that verifies this seating.

This failure of seating completely may lead to different outcomes including, but not limited to, axial displacement after loading. Axial displacement can occur inevitably due to machining tolerance and settling in different types of connections, however in conical connections, a third factor is present which is the wedge effect that induces compressive stresses on the implant in the apical direction ${ }^{53,54}$. Ko KH et al (2019) ${ }^{52}$ concluded that titanium CAD/ CAM abutments with conical connection exhibited the greatest axial displacement compared to other internal and external connections. Reduced reverse torque of the screw ${ }^{55}$ and negative occlusion ${ }^{53,54,56}$ are known drawbacks of axial displacement.

Saydin $S$ et al (2012) ${ }^{40}$ predicted that internal conical abutments showed the highest degree of rotational freedom compared to internal hex, internal octa and Tri-lobe abutments. Yao et al (2015) ${ }^{20}$ and Yao et al (2019) ${ }^{7}$ suggested that anti torsion ability relies on the frictional resistance of the cone to be higher than the torsion movement due to occlusal loads, which is not always the case clinically. Therefore, self-locking feature is added to the conical connection to resist rotation. Failure to fully engage this anti-rotation feature would lead to loss of abutment stability ${ }^{18,57}$.

Moreover, it was suggested that the larger the contact length is, the more stable the implantabutment connection would be and highlighted that if the length of the interface between abutment and implant was increased, the stability of the connection was increased in proportion to the fourth power of the contact length ${ }^{58,59}$.

Lack of internal adaptation values after cyclic loading to assess the settling and axial displacement of different connections and materials, and absence of wet conditions to mimic the oral environment are 
considered limitations of this study. Further clinical investigation is needed to confirm the outcomes of this study in oral environment.

\section{CONCLUSIONS}

From the results and within the limitations of this study, the following can be concluded:

1. Internal hex connection has better internal fit than hybrid connection with more consistent results among different materials.

2. Zirconia showed the best overall internal adaptation with consistent performance among the two connections used.

3. Low marginal gap distance of $\mathrm{CAD} / \mathrm{CAM}$ conical abutments may not necessarily indicate proper seating of the abutments.

\section{REFERENCES}

1. Gracis S, Michalakis K, Vigolo P, Vult von Steyern P, Zwahlen M, Sailer I. Internal vs. external connections for abutments/reconstructions: A systematic review. Clin. Oral Implant. Res. 2012;23(6):202-216.

2. Butignon LE, de Almeida Basilio M, Sgavioli Santo J, Arioli Filho JN. Vertical misfit of single-implant abutments made from different materials under cycling loading. Int. J. Oral Maxillofac. Implant. 2016;31:1017-1022.

3. Broggini N, McManus, LM, Hermann JS, Medina RU, Oates TW, Schenk RK, Buser D, Meolloning JT, Cochran DL. Persistent acute inflammation at the implant-abutment interface. J. Dent. Res. 2003;82:232-237.

4. Broggini N, McManus LM, Hermann JS, Medina R, Schenk RK, Buser D, Cochran DL. Peri-implant inflammation defined by the implant-abutment interface. J. Dent. Res. 2006;85:473-478.

5. Sen N, Serment IB, Gürler N. Sealing capability and marginal fit of titanium versus zirconia abutments with different connection designs. J. Adv. Prosthodont. 2019;11:105-111.

6. Tsuruta K, Ayukawa Y, Matsuzaki T, Kihara M, Koyano $\mathrm{K}$. The influence of implant-abutment connection on the screw loosening and microleakage. Int $\mathbf{J}$ Implant Dent 2018;4(1):11-16.
7. Yao KT, Kao HC, Cheng CK, Fang HW, Huang CH, Hsu MI. Mechanical performance of conical implant-abutment connections under different cyclic loading conditions. J Mech Behav Biomed Mater 2019;90:426-432.

8. Kano Sc, Binon PP, Curtis DA. A classification system to measure the implant-abutment microgap. Int $\mathrm{J}$ Oral Maxillofac Implants 2007;22(6):879-885.

9. Sahin C, Ayyildiz S. Correlation between microleakage and screw loosening at implant- abutment connection. J Adv Prosthodont 2014;6:35-38.

10. Alves DCC, de Carvalho PSP, Elias CN, Vedovatto E, Martinez EF. In vitro analysis of microbiological sealing of tapered implants after mechanical cycling. Clin Oral Inestig 2016;20(9):2437-45.

11. Scarano A, Perrotti V, Piattelli A, Laculli F, Iezzi G. Sealing capability of implant-abutment junction under cyclic loading: a toluidine blue in vitro study. J Appl Biomater Funct Mater 2015; 13(3): e293-e295.

12. Mishra SK, Chowdhary R, Kumari S. Microleakage at the different implant abutment interface: A systematic review. J. Clin. Diag. Res. 2017; 11:e10-e15.

13. Nascimento CD, Pita MS, Santos Ede S, Monesi N,Pedrazzi V, Albuquerque Junior RF, Ribeiro RF. Microbiome of titanium and zirconia dental implants abutments. Dent Mater 2016; 32:93-101.

14. El Haddad E, Gianni AB, Mancini GE, Cura F, Carinci F. Implant-abutment leaking of replace conical connection Nobel Biocare $\AA^{\circledR}$ implant system. An in vitro study of the microbiological penetration from external environment to implant abutment space. Oral Implantol 2016;9:76-82.

15. Jemt T. Failures and complications in 391 consecutively inserted fixed prostheses supported by Brånemark implants in edentulous jaws: A study of treatment from the time of prosthesis placement to the first annual checkup. Int J Oral Maxillofac Implant 1991;3:270-276.

16. Levine RA, Clem I, Wilson Jr TG, Higginbottom F, Saunders SI. A multicenter retrospective analysis of the ITI implant system used for single-tooth replacement: preliminary results at 6 or more months of loading. Int $\mathrm{J}$ oral Macillofac Implants 1997;12:237-242.

17. Pardal-Pelaez B, Montero J. Preload loss of abutment screws after dynamic fatigue in single implant-supported restorations. A systemic review. J Clin Exp Dent 2017; 9(11):e1355-e1361. 
18. Kofron MD, Carstens $\mathrm{M}, \mathrm{Fu} \mathrm{C}$, Wen HB. In vitro assessment of connection strength and stability of internal /implant-abutment connections. Clinical Biomechnics 2019;65:92-99.

19. Macedo JP, Pereira J, Vahey BR, Henriques B, Benfatti CA, Magini RS, Lopez J, Souza J. Morse taper dental implants and platform switching: the new paradigm in oral implantology. Eur J Dent 2016;10(1):148-154.

20. Yao KT, Kao HC, Cheng CK, Fang HW, Huang CH, Hsu MI. The potential risk of conical implant-abutment connections: Clin Implant Dent Relat Res 2015; 17:1208-1216.

21. Chee W, Jivraj S. Designing abutments for cement retained implant supported restorations. Br Dent J 2006; 201(9):559-563.

22. Sailer I, Zembic A, Jung RE, Hammerle CH, Mattiola A. Single tooth implant reconstructions: factors influencing the decision between titanium and zirconia abutments in anterior regions. Europ J Esthet Dent 2007;2(3):296-310.

23. Pauletto N, Lahiffe BJ, Walton JN. Complications associated with excess cement around crowns on osseointegrated implants: a clinical report. Int J oral Maxillofac Implants 1999; 14:865-868.

24. Elsayed S, Elbanna K. Effect of different fabrication materials and techniques on the retention of implant mesostructures to Ti-base abutments. Egy Dent J 2021;67: 2567-2585.

25. Atzeni E, Bassoli E, Denti L, Gatto A, Iuliano L, Minetola P, Salmi A. Tolerance analysis for cast vs machined dental implants. Procedia CIRP 2015;33:263-268.

26. Malaguti G, Denti L, Bassoli E, Franchi I et al. Dimensional tolerances and assembly accuracy of dental implants and machined versus cast-on abutments. Clin Implant Dent Relat Res 2009;13(2):134-40.

27. Ma T, Nicholls JI, Rubenstein J. Tolerance measurements of various implant components. Int J Oral Maxillofac Implants 1997;12(3):371-5.

28. Yüzügüllü B and Avci M. The implant-abutmnt interface of alumina and zirconia abutments. Clin Implant Dent Relat Res 2008;10(2):113-121.

29. Barbosa Jr S, Bacchi A, Barao V, Silva-Souza Y, Bruniera J, Caldas R, Consani R. Implant volume loss, misfit, screw loosening and stress in custom titanium and zirconia abutments. Braz Dent J 2020;31(4):374-380.
30. Gonzalo E, Vizoso B, Lopez-Suarez C, Diaz P, Pelaez J, Suarez M. Evaluation of milled titanium versus laser sintered $\mathrm{Co}-\mathrm{Cr}$ abutments on the marginal misfit in internal implant-abutment connection. Materials 2020;13:4873.

31. Edelhoff D, Schweiger J, Prandtner O, Stimmelmayr M, Güth JF. Metal-free implant-supported single-tooth restorations. Part I: Abutments and cemented crowns. Quintessence Int 2019;50:176-184.

32. Edelhoff D, Schweiger J, Prandtner O, Stimmelmayr M, Güth JF. Metal-free implant-supported single-tooth restorations. Part II: Hybrid abutment crowns and material selection. Quintessence Int 2019;50:260-269.

33. Cascos-Sanchez R, Molinero-Mourelle P, Ortega R, Agustin-Panadero R, Del Rio-Highsmith J, Gomez-Polo M. Comparative in vitro study of the bond strength of composite to carbon fiber Versus ceramic to cobalt-chromium alloys frameworks for fixed dental prostheses. Materials 2020;13:3173.

34. Elsayed S, Makke A, Elbanna K. Radiographic assessment of accuracy of fit for different conical connection abutments on tapered implants. Egy Dent J 2020;66: 2529-2539.

35. Naveau A, Rignon-Bret C, Wulfman C. Zirconia abutments in the anterior region: A systematic review of mechanical and esthetic outcomes. J Prosthet Dent 2019;121: 775-781.e1.

36. Ceramill Sintron instructions of use document. Amann Girrbach AG.

37. Abdou J , Lyons K. Rationale for the use of CAD/CAM technology in implant prosthodontics. Int J Dent 2013. Article ID768121:1-8.

38. Kim ES and Shin SY. Influence of the abutment types and the dynamic loading on initial screw loosening. $\mathrm{J}$ adv Prosthodont 2013; 5:21-8.

39. Tallarico M, Fiorellinin J, Nakajima Y, Omori Y, Takahisa I, Canullo L. Mechanical outcomes, microleakage, and marginal accuracy at the implant-abutment interface of original versus nonoriginal implant abutments: a systematic review of in vitro studies. Biomed Res Int 2018;Article ID 2958982:1-8.

40. Saidin S, Abdul Kadir M, Sulaiman E, Abu Kasim N. Effects of different implant-abutment connections on micromotion and stress distribution: prediction of microgap formation. J Dent 2012;40:467-474. 
41. Molinero-Mourelle P, Cascos-Sanchez R, Yilmaz B, Lam W, Pow E, Highsmith J, Gomez-Polo M. Effect of fabrication technique on the microgap of CAD/CAM cobaltchrome and zirconia abutments on a conical connection implant: an in vitro study. Materials 2021;14:2348.

42. Sai-Lee D, Chanatepapom P, Puasiri S, Suwannarong W, Raunglertpanyakul C. The precision between implant fixture and titanium base abutment connection and cement gap between titanium base abutment and zirconia crown. KDJ 2018;21(2):83-94.

43. Ramalho I, Witek L, Coelho P, Bergamo E, Pegoraro L, Bonfante E. Influence of abutment fabrication method on $3 \mathrm{D}$ fit at the implant-abutment connection. Int J Prosthodont 2020;33:641-647.

44. Velez J, Pelaez J, Lopez-Suarez C, Agustin-Panadero R, Tobar C, Suarez M. Influence of implant connection, abutment design and screw insertion torque on implant-abutment misfit. J Clin Med 2020;9:2365.

45. Sandoval R, Magdaleno M, Robles P, Alonso N, Ramirez G. Analysis of the mechanical behavior and effect of cyclic fatigue on the implant-abutment interface. Int J Dent Sc 2021;23(2):104-114.

46. Papavassiliou H, Kourtis S, Katerelou J, Chronopoulos V. Radiographical evaluation of the gap at the implant-abutment interface. Journal Compilation, Wiley Periodicals. Inc. 2010;22(4):235-250.

47. Alikhasi M, Salehi A, Memarian M, Tabesh M. Diagnostic value of digital radiography in gap detection of implantabutment connection with zirconia abutments in different vertical x-ray projection angles. J Clin Diagnostic Res 2018;12(5):zc15-zc18.

48. Torabi Ardekani K, Ahangari AH, Farahi L. Marginal and internal fit of CAD/CAM and slip-cast made zirconia copings. J Dent Res Dent Clin Dent Prospects 2012; $6: 42-48$.

49. Papadiochou S, Pissiotis AL. Marginal adaptation and CAD/CAM technology: a systematic review of restorative material and fabrication techniques. J Prosthet Dent 2018;119:545-551.
50. Sui X, Wei H, Wang D, Haan Y, Deng J, Wang Y et al. Experimental research on the relationship between fit accuracy and fracture resistance of zirconia abutments. J Dent 2014;42(10):1353-9.

51. Pan Y, Tsoi J, Lam W, Pow E. Implant framework misfit: a systematic review on assessment methods and clinical complications. Clin Implant Dent Relat Res 2021; 23:244-258.

52. Ko KH, Huh YH, Park CJ, Cho LR. Axial displacement in cement-retained prostheses with different implantabutment connections. Int J Maxillofac Implants 2019; 34:1098-1104.

53. Lee JH, Kim DG, Park CJ, Cho LR. Axial displacement in external and internal implant abutment connection. Clin Oral Implants Res 2014;25:e83-e89.

54. Seol HW, Heo SJ, Koak JY, Kim SK, Kim SK. Axial displacement of external and internal implant-abutment connection evaluated by linear mixed modl analysis. Int J Oral Maxillofac Implants 2015;30:1387-99.

55. Ricciardi Coppede A, de Mattos Mda G, Rodrigues RC, Rebiero RF. Effect of repeated torque/mechanical loading cycles on two different abutment types in implants with internal tapered connections: an in vitro study. Clin Oral Implants Res 2009;20:624-632.

56. Cho WR, Huh YH, Park CJ, Cho LR. Effect of cycling loading and retightening on reverse torque value in external and internal implants. J Adv Prosthodont 2015;7:288-293.

57. Tsuge T, Hagiwara Y, Matsumura H. Marginal fit and microgaps of implant-abutment interface with internal antirotation configuration. Dent Mater 2008; 27(1):29-34.

58. Bozkaya D, Muftu S, Muftu A. Evaluation of load transfer characteristics of five different implants in compact bone at different load levels by finite elements analysis. J Prosthet Dent. 2004; 92: 523-530.

59. Jeong KW, Kim JC, Yeo IS. Clinical significance of internal friction connection and micro-threads in implant-supported prostheses: A literature review. Recent Progress in Materials 2020;2(4): doi:10.21926/rpm.2004024 